\title{
Antifungal Activity and Action Mechanism of the Natural Product Cinnamic Acid Against Sclerotinia sclerotiorum
}

\author{
Yong Wang, Yang Sun, Jiali Wang, Mingxia Zhou, Miaomaio Wang, and Juntao Feng ${ }^{\dagger}$ \\ Research and Development Center of Biorational Pesticides, Northwest A \& F University, Yangling 712100, Shaanxi, China
}

\begin{abstract}
Sclerotinia stem rot caused by Sclerotinia sclerotiorum (Lib.) de Bary spreads worldwide and causes serious economic losses. Considering the development of fungicide resistance and chemical residues, it is urgently necessary to explore alternative fungicides. In this study, the activity of the natural product cinnamic acid was assessed. The $\mathrm{EC}_{50}$ values for cinnamic acid inhibition of mycelial growth of $103 \mathrm{~S}$. sclerotiorum strains ranged from 9.37 to $42.54 \mu \mathrm{g} / \mathrm{ml}$ with an average $\mathrm{EC}_{50}$ value of $18.77( \pm 3.39) \mu \mathrm{g} / \mathrm{ml}$. No cross-resistance was detected between cinnamic acid and the commonly used fungicides carbendazim or dimethachlon. After treatment with cinnamic acid, mycelia distorted with more branches, no sclerotia developed, and the oxalic acid

content decreased, whereas cell membrane permeability increased significantly. In pot experiments, cinnamic acid at 2,000 $\mu \mathrm{g} / \mathrm{ml}$ provided over $95 \%$ efficacy against both carbendazim-sensitive and carbendazim-resistant strains of S. sclerotiorum. The expression of the sclerotia development-correlated genes Sac1, Pacl, Smk1, and Pkal decreased, whereas the Cnal gene expression increased. Altogether, cinnamic acid shows potential to be a natural alternative to commercial fungicides or a lead compound to develop new fungicides for the control of Sclerotinia stem rot. The biological characteristics contribute to the understanding of the action mechanism of cinnamic acid against $S$. sclerotiorum.
\end{abstract}

The filamentous ascomycete fungus Sclerotinia sclerotiorum (Lib.) de Bary is a highly destructive plant pathogen notorious for its wide host range and worldwide distribution (Boland and Hall 1994). More than 400 species and 200 genera of higher plants, such as lettuce, soybean, sunflower, carrot, canola, and oilseed rape, can be infected by $S$. sclerotiorum at different growth stages (Abawi and Grogan 1979; Purdy 1979). Sclerotinia stem rot (SSR, also known as white mold) caused by $S$. sclerotiorum is one of the most serious fungal diseases of oilseed rape in many countries, including the United States, Australia, Canada, and China (Jo et al. 2006; Mueller et al. 2002; Smith et al. 1995; Zhou and Luo 1994). Although the oilseed rape industry in China spreads over 7.5 million hectares and could produce an annual crop value over 5 billion dollars, the SSR caused by $S$. sclerotiorum not only reduces the yield by 5 to $80 \%$ but also causes a decline in the oil quality (Shi et al. 2000; Zhou and Luo 1994).

In practice, the application of fungicides is still the primary method to control SSR, because resistant cultivars of oilseed rape have not been sufficiently developed. For more than four decades, the benzimidazole fungicide carbendazim was widely used to control SSR in China (Wang et al. 2015). However, the high level and frequency of resistance to carbendazim and decreased control efficacy have been reported not only against $S$. sclerotiorum but also in other plant pathogens (Wang et al. 2016). During the previous decade, dicarboximide fungicides, such as dimetachlone, iprodione, and procymidone, have also been used to manage SSR. Unfortunately, different

${ }^{\dagger}$ Corresponding author: J. Feng; jtfeng@126.com

Y. Wang and Y. Sun contributed equally to this work and should be considered co-first authors.

Funding: This study was sponsored by the National Natural Science Foundation of China (31801762) and the Key Industries Innovation Chain Project of Shaanxi Province (2017ZDCXL-NY-03-01)

The $\boldsymbol{e}$-Xtra logo stands for "electronic extra" and indicates that one supplementary figure and one supplementary table are published online.

Accepted for publication 8 December 2018.

() 2019 The American Phytopathological Society levels of resistance to dicarboximide fungicides have been reported in several provinces of China, including Jiangsu, Shaanxi, Hunan, and Heilongjiang (Wang et al. 2017). To reduce the chemical residue and the risk of fungicide resistance development, it is critical to explore alternative candidates to control SSR.

Currently, botanical secondary metabolites or phytochemicals from plants, such as essential oils, flavor compounds, terpenoids, glucosinolates, and chitosan, provide a series of promising alternatives for synthetic fungicides (Hettiarachi 2011; Karimi et al. 2013; Matkowski 2008). First, these compounds are environmentally friendly owing to their easy biodegradation. Second, such bioactive agents exhibit activity that provides attractive alternatives to the currently used synthetic fungicides. Third, these natural products have a potential novel action mechanism compared with commonly used fungicides that could avoid or delay the cross-resistance. Finally, natural products could also be used as the lead compounds to synthesize new drugs (Sun et al. 2017). In addition to assessing their antifungal activity, it is important to explore the action mechanism of these compounds.

Cinnamic acid (Supplementary Fig. S1) is widely used as a raw material. Its natural extract is often found in free form or in the form of esters. It can also be found in cinnamon oil, basil oil, balsam, and coca leaf. In addition, it can be synthesized artificially (Liu et al. 1995). In agriculture, cinnamic acid has long been used as a raw material for plant-derived pesticides, such as growth promoters, longacting fungicides, and fruit and vegetable preservatives (Shi et al. 2005). It can significantly increase root activity and enhance the resistance of plants to diseases. For example, when treated with cinnamic acid, the superoxide dismutase, peroxidase, and catalase activities in grafted eggplant roots increased significantly compared with those of self-rooted eggplants (Chen et al. 2010). The use of cinnamic acid in wine makes it bright and lustrous. In addition, cinnamic acid can be used as an aroma mixture in washing powder, soap, and daily cosmetics (such as sunscreen) (Hoskins 1984). Although cinnamic acid has a wide range of uses, its antifungal activity against $S$. sclerotiorum has not been extensively or systematically reported, and its action mechanism against plant pathogens is still unclear.

For these reasons, this study was conducted to (i) test the sensitivity of S. sclerotiorum to cinnamic acid; (ii) determine the crossresistance pattern between cinnamic acid and other commonly used fungicides; (iii) explore the action mechanism of cinnamic acid by investigating the effect of cinnamic acid on the biochemical 
characteristics of S. sclerotiorum; and (iv) evaluate the efficacy of cinnamic acid against SSR of rapeseed in pot experiments.

\section{Materials and Methods}

S. sclerotiorum strains and fungicides. Seventy-eight $S$. sclerotiorum isolates were collected during 2011 to 2013 from oilseed rape fields in the Jiangsu Province, and 25 S. sclerotiorum isolates were collected from the Shaanxi Province of China in 2016. The surface of the randomly collected sclerotia was disinfested using $1 \% \mathrm{NaClO}$ for $1 \mathrm{~min}$, sterile distilled water for 30s, and then air dried. After the disinfested sclerotia were placed on potato dextrose agar (PDA) plates amended with $100 \mu \mathrm{g} / \mathrm{ml}$ of streptomycin sulfate at $25^{\circ} \mathrm{C}$ for 3 days, a single sclerotium of each strain was transferred and stored on PDA slants at $4^{\circ} \mathrm{C}$ (Hou et al. 2018).

Technical-grade carbendazim (98\% active ingredient [a.i.]) and dimetachlone (95\% a.i.), provided by Wenzhou Pesticide Factory, Zhejiang Province, China, were dissolved in $0.1 \mathrm{M}$ hydrochloric acid $(\mathrm{HCl})$ and methanol at $10 \mathrm{mg} / \mathrm{ml}$, respectively, as stock solutions. Technical-grade cinnamic acid (96\% a.i.), provided by Macklin Biochemical Co., Shanghai, China, was dissolved in methanol at 10 $\mathrm{mg} / \mathrm{ml}$ as a stock solution.

Sensitivity to cinnamic acid in vitro. To test the sensitivity of the 103 S. sclerotiorum isolates to cinnamic acid, mycelial plugs $(5 \mathrm{~mm}$ in diameter) cut from the margin of an actively growing colony were transferred to a series of PDA plates containing 0, 3.125, 6.25, 12.5, 25,50 , or $100 \mu \mathrm{g} / \mathrm{ml}$ of cinnamic acid. Sensitivity assays were based on the measurement of mycelial growth inhibition on PDA medium as described previously (Duan et al. 2013). The 50\% effective concentration $\left(\mathrm{EC}_{50}\right)$ value for each isolate was calculated by plotting the percentage of mycelial growth inhibition against the $\log _{10}$ fungicide concentrations in three independent measurements (Alberoni et al. 2005; Duan et al. 2013). There were three replicates in each treatment, and the experiment was performed twice.

Cross-resistance test on PDA medium. Cross-resistance between cinnamic acid and other fungicides belonging to several chemical classes was investigated using $12 \mathrm{~S}$. sclerotiorum isolates exhibiting different sensitivities to carbendazim and dimethachlon (Table 1). The final concentrations were $0,0.0625,0.125,0.25$, $0.5,1$, and $2 \mu \mathrm{g} / \mathrm{ml}$ for carbendazim- or dimethachlon-sensitive isolate; $0,0.625,1.25,2.5,5$, and $10 \mu \mathrm{g} / \mathrm{ml}$ for dimethachlon-resistant isolate; and $0,31.25,62.5,125,250$, and $500 \mu \mathrm{g} / \mathrm{ml}$ for carbendazimresistant isolate. For each of the abovementioned fungicides, the $\mathrm{EC}_{50}$ values were measured as described above. The crossresistance between cinnamic acid and other fungicides was determined by analyzing the relationships of the sensitivities (Wang et al. 2016). There were three replicates in each treatment, and the experiment was performed twice.

Effect of cinnamic acid on the mycelial morphology and sclerotia production. Mycelial plugs cut from the margin of a 2day-old colony (strains JK19, TZ5, and YX36, randomly selected) were transferred onto PDA plates amended with cinnamic acid at their $\mathrm{EC}_{50}$ values. PDA plates without cinnamic acid treatment were used as a control. After $24 \mathrm{~h}$ at $25^{\circ} \mathrm{C}$, the margin of the colony $(10 \times$ $10 \mathrm{~mm}$ ) was cut and placed on a glass slide. The morphology of the top mycelia was observed using a scanning electron microscope (SEM, JSM-6360LV, Japan).

To test the effect of cinnamic acid on sclerotia production, mycelial plugs were treated as described above. After the PDA plates were incubated at $25^{\circ} \mathrm{C}$ for 4 weeks in darkness, the sclerotia production of each colony was subjectively assessed. The experiment was repeated three times in triplicate for each treatment.

Effect of cinnamic acid on oxalic acid content. The three strains (JK19, TZ5, and YX36) were used to assay the oxalic acid content as described by Duan et al. (2013) with minor modifications. Under acidic conditions, iron (i) and oxalate form a complex that discolors the complex of iron (i) and sulfosalicylic acid. Therefore, the content of oxalate could be measured indirectly by determining the intensity of the color of the complex at $510 \mathrm{~nm}$ using a spectrophotometer. First, $1.2 \mathrm{ml}$ of sulfosalicylic acid solution $(5 \mathrm{mg} / \mathrm{ml}), 2 \mathrm{ml}$ of $\mathrm{FeCl}_{3}$ solution $(0.5 \mathrm{mg} / \mathrm{ml})$, and $20 \mathrm{ml}$ of $\mathrm{HCl}-\mathrm{KCl}$ buffer $(\mathrm{KCl} 50 \mathrm{mM}, \mathrm{pH}=2)$ were added to a 50-ml centrifuge tube. Second, different volumes $(0,0.1,0.2,0.4$, or $0.8 \mathrm{ml})$ of sodium oxalate solution $(2 \mathrm{mg} / \mathrm{ml})$ were added. Third, sterilized water was added to each of the centrifuge tubes to increase the volume to $25 \mathrm{ml}$, and then the centrifuge tubes were vortex stirred for $10 \mathrm{~s}$ and incubated for $30 \mathrm{~min}$ at $25^{\circ} \mathrm{C}$. Sterilized water was used as a control. The absorbance was measured at $510 \mathrm{~nm}$ with a spectrophotometer. Finally, the standard curve was established by plotting absorbance against sodium oxalate concentration.

For each of the three isolates, 10 mycelial plugs $(5 \mathrm{~mm}$ in diameter) cut from the advancing margin of 2-day-old colonies were placed in 250-ml flasks containing $100 \mathrm{ml}$ of potato dextrose broth (PDB; PDA without agar) treated with cinnamic acid at their $\mathrm{EC}_{50}$ values. Flasks without cinnamic acid were used as a control. The flasks were kept in a rotary shaker at $175 \mathrm{rpm}$ and $25^{\circ} \mathrm{C}$ for 2 days and then centrifuged at 1,500 rpm for $10 \mathrm{~min}$. A spectrophotometer was used to determine the absorbance of the oxalic acid content in the supernatants at $510 \mathrm{~nm}$. The oxalic acid content in the supernatants was calculated using the standard curve. The unit of oxalic acid content was expressed as the ratio of oxalic acid in PDB to mycelial dry weight. Three flasks per treatment were used, and the experiment was repeated three times.

Effect of cinnamic acid on the cell membrane permeability. Three strains (JK19, TZ5, and YX36, randomly selected) were used for the cell membrane permeability test. Ten mycelial plugs taken from the margin of each colony were placed in 250-ml flasks containing $100 \mathrm{ml}$ of PDB. After the flasks were shaken at $175 \mathrm{rpm}$ and $25^{\circ} \mathrm{C}$ for $36 \mathrm{~h}$, partial flasks were amended with cinnamic acid at their $\mathrm{EC}_{50}$ values. After shaking for another $12 \mathrm{~h}$, the mycelia were collected and washed with distilled water three times. Then $0.5 \mathrm{~g}$ of mycelia was placed in a $50-\mathrm{ml}$ centrifuge tube containing $20 \mathrm{ml}$ of distilled water, and the electrical conductivity of the distilled water was

Table 1. Analysis of cross-resistance ${ }^{z}$

\begin{tabular}{|c|c|c|c|}
\hline Strains & $\mathrm{EC}_{50}$ for carbendazim $(\mu \mathrm{g} / \mathrm{ml})$ & $\mathrm{EC}_{50}$ for dimethachlon $(\mu \mathrm{g} / \mathrm{ml})$ & $\mathrm{EC}_{50}$ for cinnamic acid $(\mu \mathrm{g} / \mathrm{ml})$ \\
\hline TZ51 & 0.1128 & 0.2145 & 27.66 \\
\hline JK19 & 0.2022 & 0.1932 & 23.33 \\
\hline JY11 & 0.2178 & 0.3281 & 16.90 \\
\hline CS52 & 0.1860 & 0.2810 & 21.22 \\
\hline $\mathrm{TZ8}$ & $>100$ & 0.2134 & 21.04 \\
\hline YX36 & $>100$ & 0.2863 & 19.87 \\
\hline JD68 & $>100$ & 0.3102 & 23.45 \\
\hline HA53 & $>100$ & 0.1953 & 23.76 \\
\hline LYG82 & 0.2351 & 3.25 & 20.17 \\
\hline HA45 & 0.2197 & 2.97 & 15.82 \\
\hline CZ138R1 & 0.1268 & 3.19 & 21.02 \\
\hline CZ138R2 & 0.1304 & 2.17 & 24.52 \\
\hline
\end{tabular}

${ }^{\mathrm{z}} \mathrm{CZ138R} 1$ and CZ138R2 were laboratory-induced dimethachlon-resistant isolates. Other strains were collected from fields and stored in our laboratory. $\mathrm{EC}_{50}=$ $50 \%$ effective concentration. 
determined after $0.5,1,2,3,4,5$, and $6 \mathrm{~h}$ using a conductivity meter (S320 Seven Compact, Mettler Toledo, Switzerland). After $6 \mathrm{~h}$, the distilled water containing the mycelia was boiled for $5 \mathrm{~min}$ and cooled to room temperature to determine the final conductivity. Three replicates per treatment were used, and the experiment was conducted three times.

Efficacy of cinnamic acid against $S$. sclerotiorum in pot experiments. Carbendazim-sensitive isolate JK19 and carbendazim-resistant isolate YX36 were used in the efficacy test. Oilseed rape plants (Qinyou 10, Shaanxi Qinfeng Seed Science Company) were cultured at $25^{\circ} \mathrm{C}$. When the plants had five to seven leaves, each plant was sprayed with water (control), cinnamic acid at $500,1,000$, and $2,000 \mu \mathrm{g} / \mathrm{ml}$, or carbendazim at $200 \mu \mathrm{g} / \mathrm{ml}$. After air drying, three leaves at a similar growth stage of each plant were wounded with a sterilized needle (avoiding the primary vein) and inoculated with a mycelial plug cut from the edge of a 2-day-old colony of the isolate JK19 or YX36. The inoculated plants were maintained in a growth chamber $\left(20\right.$ to $25^{\circ} \mathrm{C}, 12$-h photoperiod, and $85 \%$ relative humidity). After 3 days, oilseed rape leaves were cut off, and the lesion diameter was measured in two perpendicular directions and averaged. The control efficacy was calculated by [(lesion diameter of control- lesion diameter of treatment)/(lesion diameter of control$0.5)] \times 100$. The experiment was performed twice with three plants per treatment.

Expression level of the genes correlated with sclerotia production. Previous studies had demonstrated that the adenylate cyclase Sacl gene (SS1G_07715.1), Pacl gene (SS1G_ 07355.1), Smk1 gene (SS1G_11866.1), Cnal gene (SS1G_01788.1), Pkal gene (SS1G_03171.1), and Pka2 gene (SS1G_01124.1) were involved and essential in sclerotia production (Chen et al. 2004; Erental et al. 2008; Harel et al. 2006; Jurick and Rollins 2007; Rollins 2003). Therefore, the expression level of these genes was determined

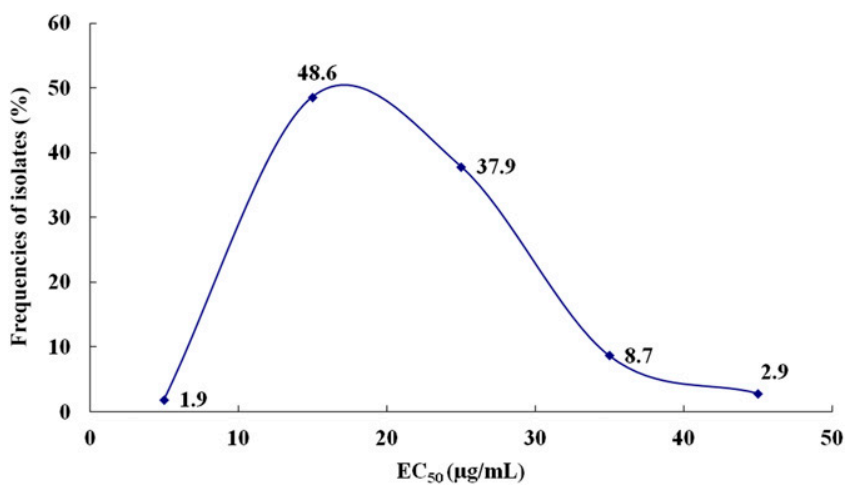

Fig. 1. Frequency distribution of cinnamic acid $E C_{50}$ values for 103 isolates of Sclerotinia sclerotiorum by inhibition of mycelial growth. using quantitative real-time polymerase chain reaction (qRT-PCR) according to a previous study (Wang et al. 2015). Total RNA was extracted from S. sclerotiorum isolates JK19 (sensitive to carbendazim) and YX36 (resistant to carbendazim) using the TRIzol Reagent (Invitrogen). The extract RNA was treated with DNase and used for cDNA synthesis using a PrimeScript RT reagent kit (TaKaRa, Japan) (Duan et al. 2013). The primers used for qRT-PCR are listed in Table 2. qRT-PCR was performed using SYBR Premix Ex Taq on a CFX96 Touch Real-time PCR detection system (Bio-Rad, U.S.A.) according to the manufacturer's instructions. Each treatment had three technical replicates, and the experiment was conducted with three biological replicates. All the data were normalized to actin gene expression, and the qRT-PCR data from the three biological replicates were used to calculate the mean and standard deviation for the expression level of each gene.

Data analysis. All data obtained above were analyzed with an analysis of variance using SPSS 22.0 (Statistical Package for the Social Sciences, SPSS, U.S.A.). Significant difference analysis among the data of $\mathrm{EC}_{50}$ values and the biological characteristics were determine using Fisher's LSD test $(P=0.05)$. Gene expression was analyzed using an independent Student's $t$ test.

\section{Results}

Sensitivity of $S$. sclerotiorum to cinnamic acid. The 103 S. sclerotiorum isolates used in this study had not been previously exposed to cinnamic acid. The $\mathrm{EC}_{50}$ values of the $103 \mathrm{~S}$. sclerotiorum isolates to cinnamic acid ranged from 9.37 to $42.54 \mu \mathrm{g} / \mathrm{ml}$ with an average $\mathrm{EC}_{50}$ value of $18.77 \pm 3.39 \mu \mathrm{g} / \mathrm{ml}$ (Supplementary Table S1). There were no significant differences among the $\mathrm{EC}_{50}$ values of the $25 \mathrm{~S}$. sclerotiorum isolates collected from Shaanxi Province and the $\mathrm{EC}_{50}$ values of the $78 \mathrm{~S}$. sclerotiorum isolates collected from Jiangsu Province. The frequency distribution of the $\mathrm{EC}_{50}$ values was unimodal with a narrow range (Fig. 1), and the variation factor value (the ratio by the $\mathrm{EC}_{50}$ values of the least to most sensitive strain) was 4.54 .

Cross-resistance analysis. Among the 12 isolates, four were resistant to carbendazim and four were resistant to dimethachlon. The sensitivity to cinnamic acid differed from each other, and the $\mathrm{EC}_{50}$ values ranged from 16.32 to $29.35 \mu \mathrm{g} / \mathrm{ml}$. As expected, there was no clear correlation between the $\mathrm{EC}_{50}$ values for cinnamic acid and for carbendazim or dimethachlon (Table 1). This suggested there was no cross-resistance among the three fungicides carbendazim, dimethachlon, or cinnamic acid, which could be explained by the different action mechanism of these fungicides.

Effect of cinnamic acid on the mycelial morphology and sclerotia production. The change in mycelial morphology was observed using SEM. After treatment with cinnamic acid at their $\mathrm{EC}_{50}$ values, the hyphae of $S$. sclerotiorum were contorted with an increased offshoot on top (Fig. 2), whereas the hyphae without fungicide treatment were natural.

Table 2. Quantitative real-time polymerase chain reaction (qRT-PCR) primers used in this study

\begin{tabular}{|c|c|c|}
\hline Primer & Sequence $\left(5^{\prime}-3^{\prime}\right)$ & Use \\
\hline P1 & CATCTGGCGGGCGCATTCCTC & qRT-PCR primers for the $S a c l$ gene \\
\hline $\mathrm{P} 2$ & GATGCGTTGTCGCAAGCTTCACAG & \\
\hline P3 & TGCTGGTTCACCTTCTGTT & qRT-PCR primers for the $P a c 1$ gene \\
\hline P4 & CAGGCTTCTCCTCAGTCTTTA & \\
\hline P5 & ATGTATGGTCTGTTGGGTGTA & qRT-PCR primers for the $S m k 1$ gene \\
\hline P6 & GATTTGATGCCGTAGTAATCT & \\
\hline P7 & GATGCTGGTTACCGAATG & qRT-PCR primers for the Cnal gene \\
\hline P8 & AGCGGCTTTGTTGTTGTA & \\
\hline P9 & АТССТСССАААТССТТСТА & qRT-PCR primers for the $P k a l$ gene \\
\hline P10 & GTCCCTCAGCATCCAATAA & \\
\hline P11 & GGCATTTACAGAAAGAGGG & qRT-PCR primers for the $P k a 2$ gene \\
\hline $\mathrm{P} 12$ & ATAATCCAAAGTCGCACAA & \\
\hline actin-F & CCCCAGCGTTCTACGTCT & qRT-PCR primers for analysis of actin \\
\hline actin-R & CATGTCAACACGAGCAATG & gene expression \\
\hline
\end{tabular}



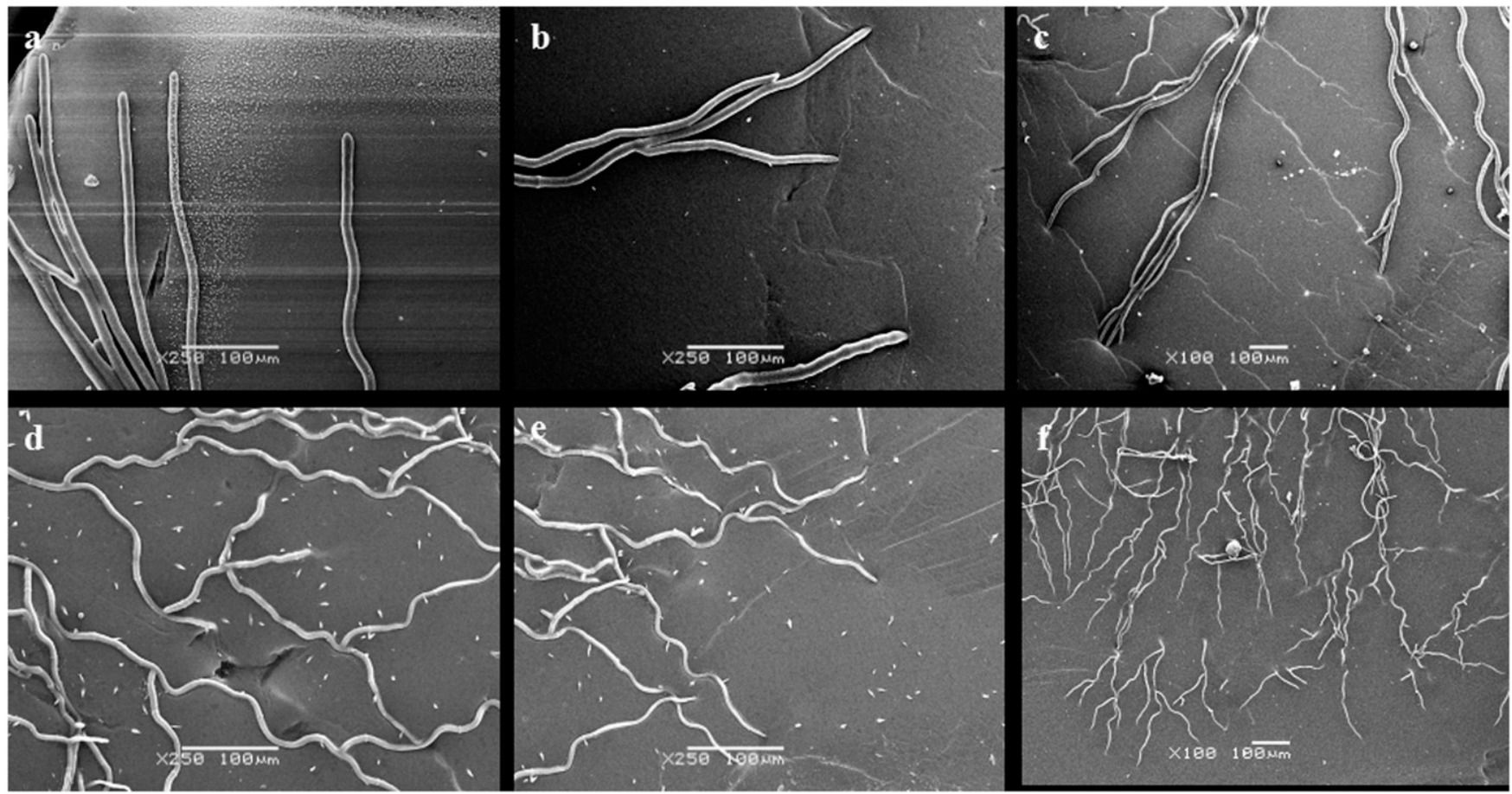

Fig. 2. Effect of cinnamic acid on hyphal morphology of Sclerotinia sclerotiorum: $\mathbf{a}, \mathbf{b}$, and $\mathbf{c}$, untreated controls; and $\mathbf{d}$, e and f, treated with cinnamic acid at their EC 50 values (strains JK19, TZ5, and YX36, respectively).

\section{JK19}
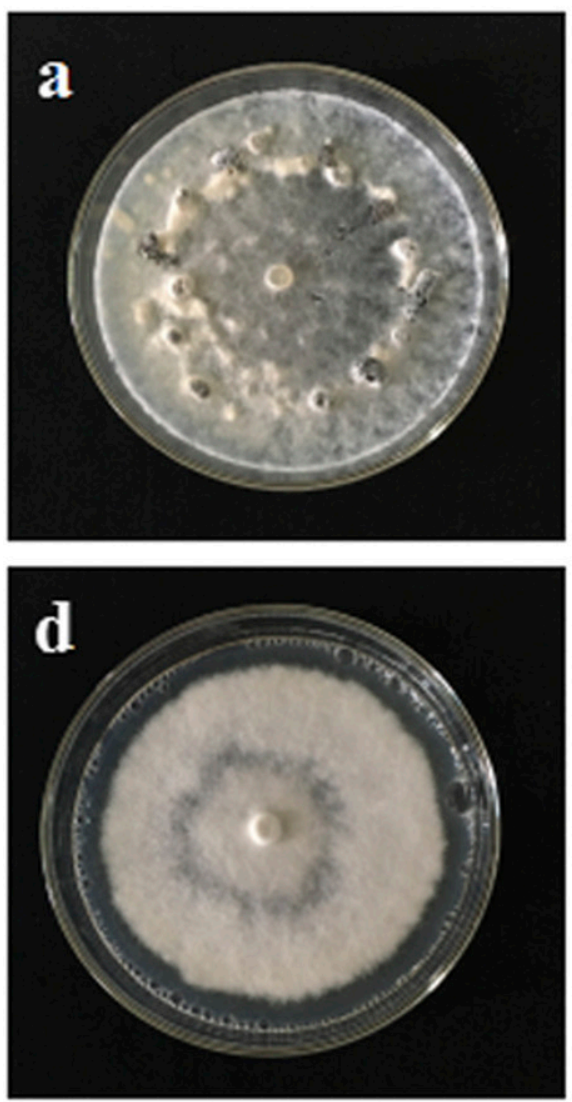

TZ5
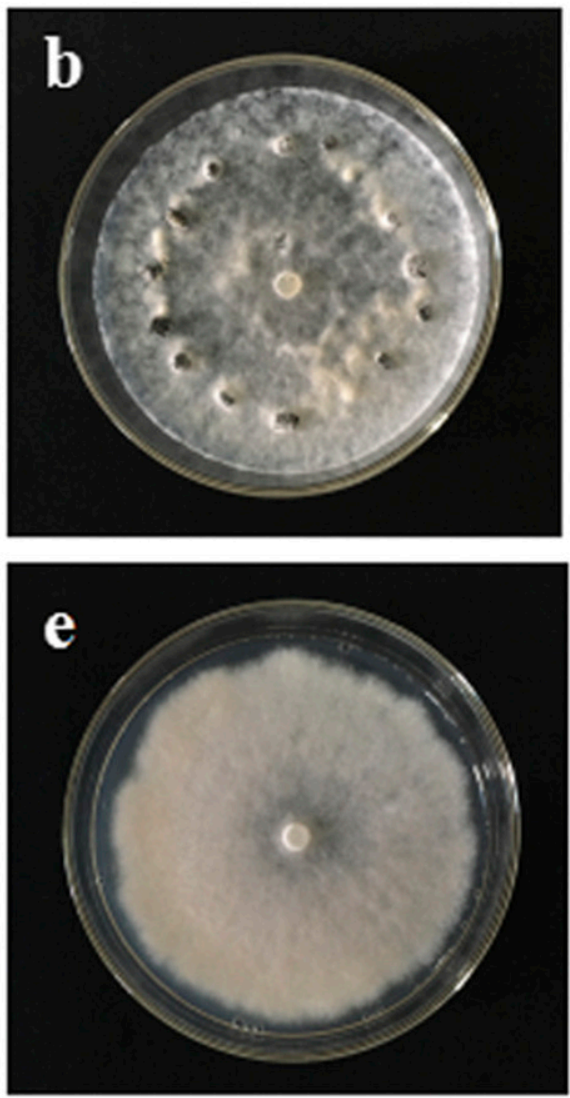

YX36
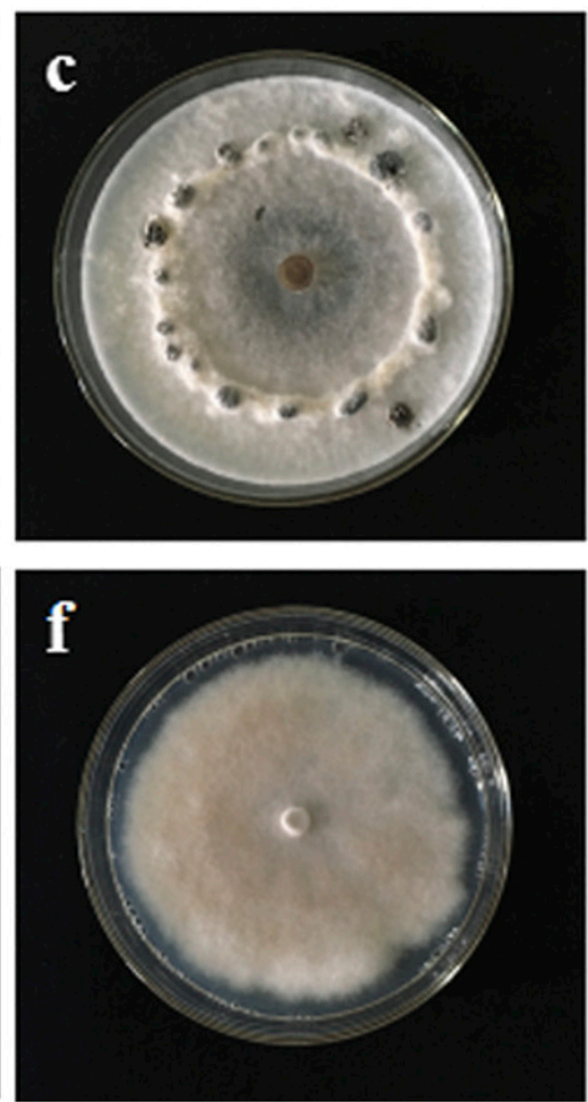

Fig. 3. Sclerotial production by Sclerotinia sclerotiorum: a, b and c, untreated control; and d, e and f, treated with cinnamic acid at their EC 50 values (strains JK19, TZ5, and YX36, respectively). 
After incubation at $25^{\circ} \mathrm{C}$ in darkness for 4 weeks, sclerotia could be observed on the colony of the three $S$. sclerotiorum isolates JK19, TZ5, and YX36. However, there were no sclerotia produced when the isolates were treated with cinnamic acid at their $\mathrm{EC}_{50}$ values (Fig. 3). This indicated that cinnamic acid could inhibit the development of sclerotia.

Effect of cinnamic acid on oxalic acid content. Oxalic acid content in the mycelia was examined by measuring the absorbance at $510 \mathrm{~nm}$ of the inoculated PDB treated with or without cinnamic acid. After treatment with cinnamic acid at their $\mathrm{EC}_{50}$ values, the oxalic acid contents of the three wild-type strains JK19, TZ5, and YX36 were significantly decreased compared with their parental isolates (Fig. 4).

Effect of cinnamic acid on the cell membrane permeability. As shown in Figure 5, the relative conductivity increased over time whether the strains were treated with or without cinnamic acid. However, the relative conductivity of the $S$. sclerotiorum strains JK19, TZ5, and YX36 treated with cinnamic acid was always higher than that of the corresponding control strains. The results suggested that cinnamic acid might damage the cell membrane, leading to the release of intracellular electrolytes in S. sclerotiorum.

Control efficacy of cinnamic acid in pot experiments. On oilseed rape plants, large lesions developed from both the carbendazim-sensitive isolate JK19 and the carbendazim-resistant isolate YX36 (Fig. 6). As expected, only $26.27 \%$ efficacy was obtained by carbendazim at $200 \mu \mathrm{g} / \mathrm{ml}$ when the plants were inoculated with the carbendazim-resistant isolate YX36. In contrast, when treated with cinnamic acid at $2,000 \mu \mathrm{g} / \mathrm{ml}$, over $95 \%$ efficacy was obtained whether the plants were inoculated with the carbendazimsensitive isolate JK19 or the carbendazim-resistant isolate YX36. Over $80 \%$ efficacy was obtained when the plants were treated with cinnamic acid at $1,000 \mu \mathrm{g} / \mathrm{ml}$, which was nearly equal to the efficacy obtained by carbendazim at $200 \mu \mathrm{g} / \mathrm{ml}$ when the plants were inoculated with carbendazim-sensitive isolate JK19. In addition, the treatment with cinnamic acid at $500 \mu \mathrm{g} / \mathrm{ml}$ exhibited over $60 \%$ efficacy whether the plants were inoculated with carbendazim-sensitive or resistant isolates (Table 3).

Gene expression levels. qRT-PCR was used to test the effect of cinnamic acid on the expression of genes correlated with sclerotia production in $S$. sclerotiorum. Relative to the expression in their wild-type strains, the $S a c 1, P a c 1, P k a 1$, and $S m k 1$ genes exhibited decreased expression after being treated with cinnamic acid, whereas the Cnal gene exhibited significantly increased expression over 1.40 -fold both in carbendazim-sensitive isolate JK19 and carbendazim-resistant isolate YX36. Interestingly, no significant changes were found in the expression level of the $P k a 2$ gene whether it was treated with cinnamic acid or not (Fig. 7).

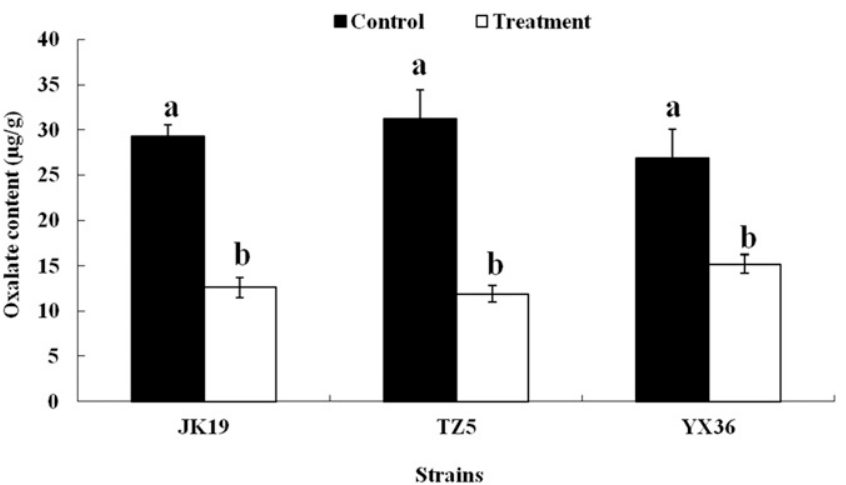

Fig. 4. Oxalic acid content of Sclerotinia sclerotiorum strains JK19, TZ5, and YX36 treated with cinnamic acid or not. Bars indicate standard deviation of three experiments. Values in columns followed by the same letters are not significantly different according to Fisher's protected LSD test $(P=0.05)$.

\section{Discussion}

Oilseed rape is an important economic crop throughout the world, especially in China, which is one of the oldest countries in the world to cultivate oilseed rape. The sowing area and total output of rapeseed in China have long been the highest in the world, accounting for the total amount and total output of 20.57 and $22.23 \%$ of rapeseed in the world, respectively (Shen et al. 2007). However, SSR of rapeseed caused by $S$. sclerotiorum has imposed serious limitations on oilseed rape production all over the world. Currently, fungicide application is still the main method in controlling SSR owing to the limit of resistant cultivars. The high selective pressure resulting from extensive fungicide use, however, has increased the development of fungicide-resistant pathogens (Duan et al. 2013; Firoz et al. 2016; Ma et al. 2009; Xu et al. 2015). Therefore, exploration of new alternative fungicides with a different mode of action for resistance management of $S$. sclerotiorum is urgently necessary.
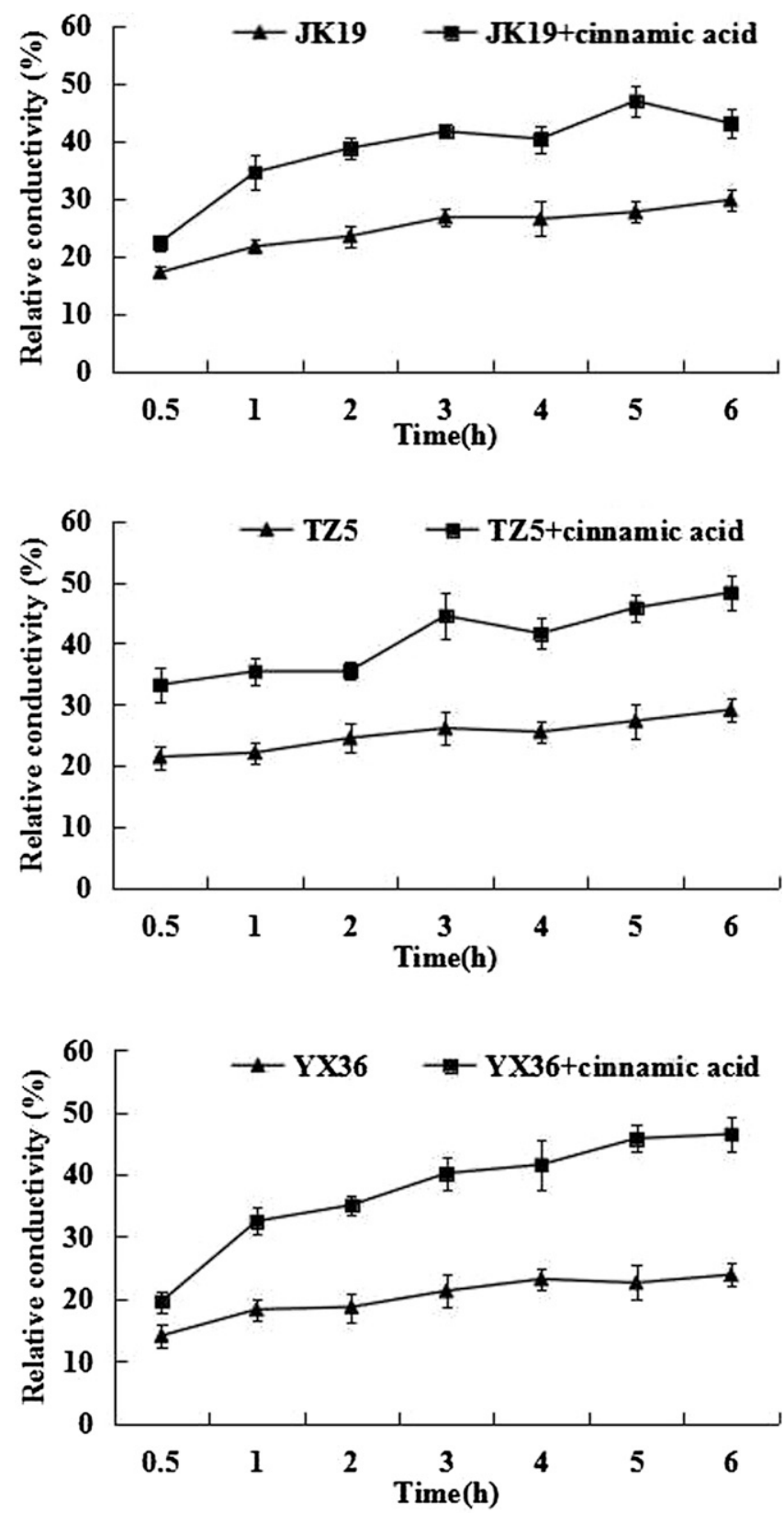

Fig. 5. Relative conductivity of Sclerotinia sclerotiorum strains JK19, TZ5, and YX36 treated with cinnamic acid or not. Bars indicate standard deviation of three experiments. 
Considering the resistance and residue of chemical fungicides and the public demand for environmental protection and human safety, pesticides must have the advantages of high efficiency, low toxicity, and human and environmental safety. For these reasons, natural products extracted from plants are receiving more attention and interest. Cinnamic acid has a wide range of uses in agriculture, industry, and medicine (Liu et al. 1995). Because cinnamic acid has antiseptic and bactericidal effects, it can also be used to preserve fruits, vegetables, and other foods (Hoskins 1984).

In this study, we tested the sensitivity of $S$. sclerotiorum to cinnamic acid. The $\mathrm{EC}_{50}$ values of $103 \mathrm{~S}$. sclerotiorum isolates to cinnamic acid ranged from 9.37 to $42.54 \mu \mathrm{g} / \mathrm{ml}$ with an average value of $18.77 \mu \mathrm{g} / \mathrm{ml}$, which was nearly equal to the activity of the natural product lansiumamide and even better than the activity of eugenol against S. sclerotiorum reported previously (Yan et al. 2018). As expected, there was no cross-resistance between cinnamic acid and the other two commonly used fungicides, carbendazim or dimethachlon, which could be explained by their different action mechanisms. Notably, in pot experiments, more than $80 \%$ efficacy was obtained when treated with cinnamic acid at $1,000 \mu \mathrm{g} / \mathrm{ml}$, which was nearly equal to the efficacy obtained by carbendazim at $200 \mu \mathrm{g} / \mathrm{ml}$. In addition, our effort to induce cinnamic acid-resistant isolates of $S$. sclerotiorum was unsuccessful, which demonstrated that the fungi might not easily develop resistance to cinnamic acid All the data above suggested that cinnamic acid has strong antifungal activity and could be used as a potential alternative fungicide to control SSR.

Natural products have been used as botanical fungicides for a long time. In addition to their direct antifungal activity, they can also be

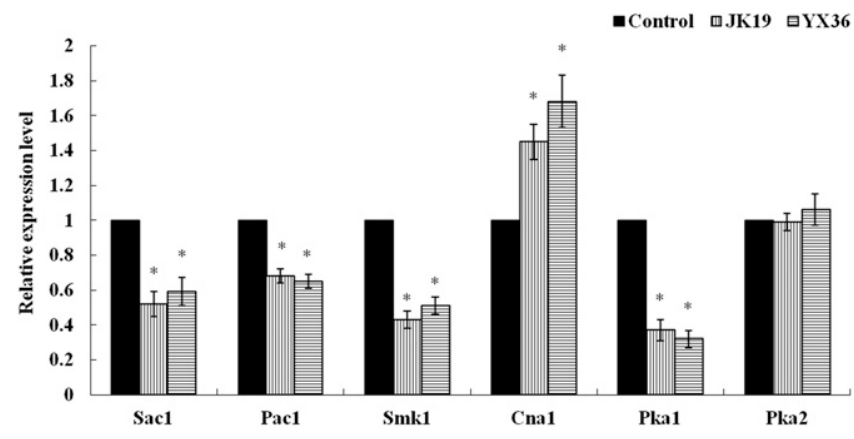

Fig. 7. Relative expression level of the genes correlated with sclerotial production in Sclerotinia sclerotiorum. Each value represents the mean \pm standard error. Statistical differences were detected with independent sample $t$ tests (asterisk [ $\left.{ }^{*}\right]$ indicates $P<$ $0.05)$.

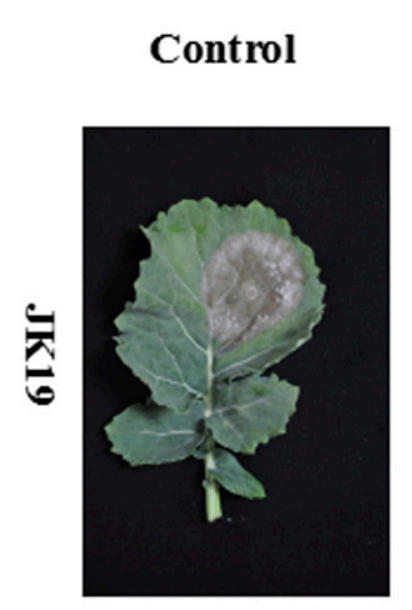

\section{carbendazim $200 \mu \mathrm{g} / \mathrm{mL}$}
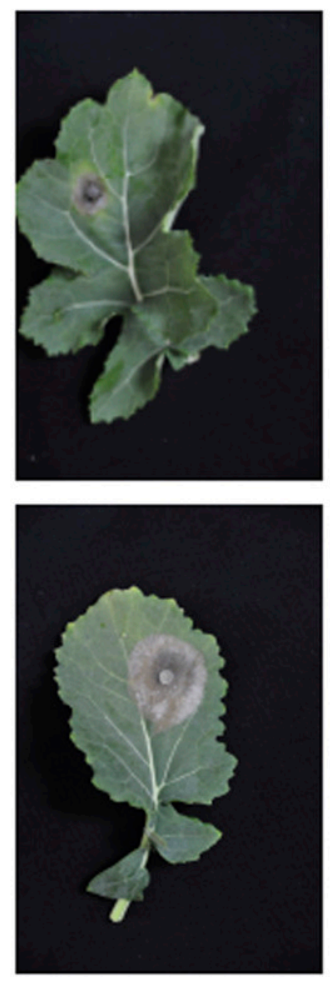

\section{cinnamic acid} $500 \mu \mathrm{g} / \mathrm{mL}$
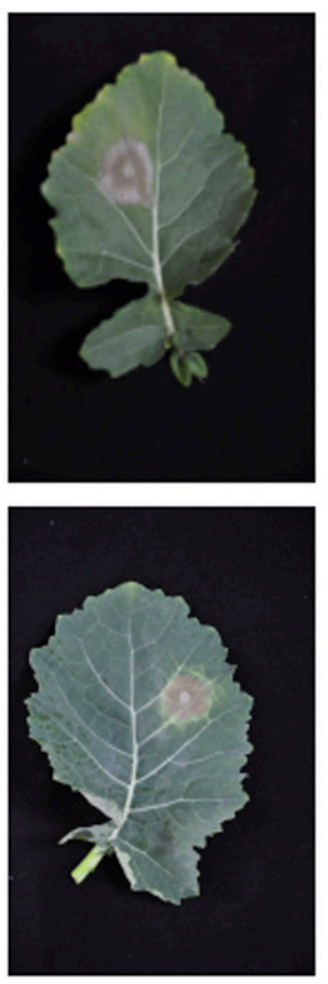

cinnamic acid $1000 \mu \mathrm{g} / \mathrm{mL}$
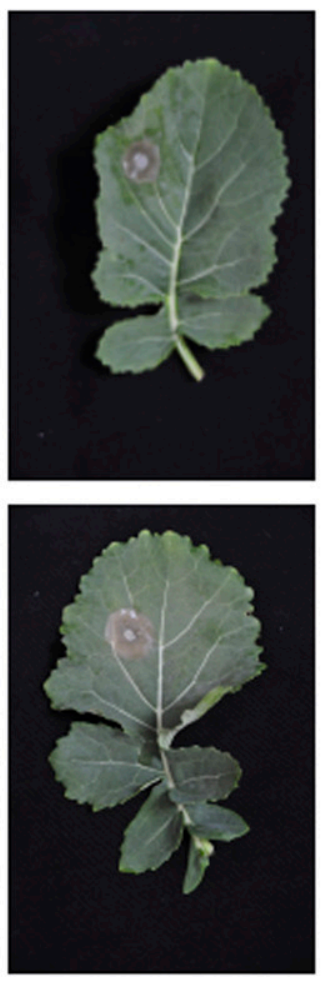

\section{cinnamic acid $2000 \mu \mathrm{g} / \mathrm{mL}$}
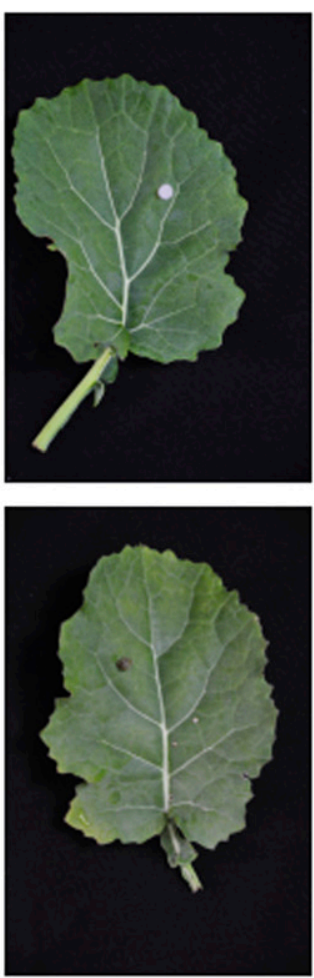

Fig. 6. Efficacy of cinnamic acid against Sclerotinia sclerotiorum in pot experiments. JK19 = carbendazim-sensitive isolate, and YX36= carbendazim-resistant isolate.

Table 3. Efficacy of cinnamic acid against Sclerotinia sclerotiorum in pot experiments ${ }^{\mathrm{x}}$

\begin{tabular}{|c|c|c|c|c|}
\hline \multirow[b]{2}{*}{ Treatment } & \multicolumn{2}{|c|}{ Plants inoculated with JK19 } & \multicolumn{2}{|c|}{ Plants inoculated with YX36 } \\
\hline & Lesion diameter $(\mathrm{cm})^{\mathrm{y}}$ & Control efficacy $(\%)^{\mathbf{z}}$ & Lesion diameter $(\mathrm{cm})$ & Control efficacy $(\%)$ \\
\hline Cinnamic acid $(500 \mu \mathrm{g} / \mathrm{ml})$ & $2.05 \mathrm{~b}$ & 62.65 & $1.98 \mathrm{c}$ & 64.34 \\
\hline Cinnamic acid $(1,000 \mu \mathrm{g} / \mathrm{ml})$ & $1.20 \mathrm{c}$ & 83.13 & $1.32 \mathrm{c}$ & 80.24 \\
\hline Cinnamic acid $(2,000 \mu \mathrm{g} / \mathrm{ml})$ & $0.63 \mathrm{~d}$ & 96.87 & $0.65 \mathrm{~d}$ & 96.39 \\
\hline Carbendazim $(200 \mu \mathrm{g} / \mathrm{ml})$ & $1.11 \mathrm{c}$ & 85.30 & $3.56 \mathrm{~b}$ & 26.27 \\
\hline Water control & $4.65 \mathrm{a}$ & $\ldots$ & $4.25 \mathrm{a}$ & $\ldots$ \\
\hline
\end{tabular}

$\times \mathrm{JK} 19=$ carbendazim-sensitive isolate, and YX36 = carbendazim-resistant isolate.

y Values in columns followed by the same letters are not significantly different according to Fisher's protected LSD test $(P=0.05)$.

${ }^{\mathrm{z}}$ Control efficacy $=[($ lesion diameter of control - lesion diameter of treated group $) /($ lesion diameter of control -0.5$)] \times 100 \%$. 
used as a lead compound to synthesize drugs with a novel action mechanism. For example, strobilurin fungicides, such as azoxystrobin, picoxystrobin, and pyraclostrobin, were synthesized based on the chemical structure of strobilurin A (Becker et al. 1981), and the pyrrole compounds fenpiclonil and fludioxonil were synthesized based on the chemical structure of the natural compound pyrrolnitrin (Pillonel and Meyer 1997). Although the chemical structure of cinnamic acid is simple, cinnamic acid derivatives, such as cinnamamide, methyl cinnamate, and methoxycinnamic acid, have been widely studied. Research to synthesize novel drugs based on the chemical structure of cinnamic acid is in progress.

Although the exploration for highly active natural products is an important approach to develop new pesticides, the study of their molecular target is more important. Previous studies have demonstrated that the sclerotia of $S$. sclerotiorum could survive in soil for more than 6 years, even in unfavorable environmental conditions, which is the primary reason that $S$. sclerotiorum can survive and propagate over the long term (Jurick and Rollins 2007). In addition, the oxalic acid secreted by $S$. sclerotiorum plays important roles in pathogenicity, sclerotia development, and other aspects (Cessna et al. 2000; Rollins and Dickman 2001; Williams et al. 2011). S. sclerotiorum lost the ability to infect and no sclerotia developed in the oxalatedeficient mutants (Godoy et al. 1990). In this study, the oxalic acid content in the mycelia decreased significantly after treatment with cinnamic acid, and they lost the ability to produce sclerotia. In addition, the expression of the genes correlated with sclerotia development was examined using qRT-PCR. After treatment with cinnamic acid, the Sacl, Pacl, Smkl, and Pkal gene expression decreased. However, Cnal gene expression increased. These changes could be explained by the positive regulatory effects of the Sacl, Pacl, Smkl, and Pkal genes, whereas the Cnal gene may have negative regulatory effects on sclerotia development, which merits further study.

All these data suggest that cinnamic acid has promising antifungal activity against $S$. sclerotiorum. It cannot only inhibit mycelial growth but also inhibit the development of sclerotia and prevent the secretion of oxalic acid, which could indirectly disrupt the disease cycle. To our knowledge, this is the first report on the sensitivity and pharmacological characteristics of $S$. sclerotiorum to the natural product cinnamic acid. Cinnamic acid exhibits potential value and could be a promising alternative to benzimidazole or dicarboximide fungicides in controlling SSR. The research to synthesize novel drugs based on the chemical structure of cinnamic acid and to explore the action mechanism of cinnamic acid against plant pathogens is in progress in our laboratory.

\section{Literature Cited}

Abawi, G. S., and Grogan, R. G. 1979. Epidemiology of diseases caused by Sclerotinia species. Phytopathology 69:899-904.

Alberoni, G., Collina, M., Pancaldi, D., and Brunelli, A. 2005. Resistance to dicarboximide fungicides in Stemphylium vesicarium of Italian pear orchards. Eur. J. Plant Pathol. 113:211-219.

Becker, W. F., Von, J. G., Anke, T., and Steglich, W. 1981. Oudemansin, strobilurin A, strobilurin B and myxothiazol: New inhibitors of the bc1 segment of the respiratory chain with an E- $\beta$-methoxyacrylate system as common structural element. FEBS Lett. 132:329-333.

Boland, G. J., and Hall, R. 1994. Index of plant hosts of Sclerotinia sclerotiorum. Can. J. Plant Pathol. 16:93-108.

Cessna, S. G., Sears, V. E., Dickman, M. B., and Low, P. S. 2000. Oxalic acid, a pathogenicity factor for Sclerotinia sclerotiorum, suppresses the oxidative burst of the host plant. Plant Cell 12:2191-2200.

Chen, C. B., Harel, A., Gorovoits, R., Yarden, O., and Dickman, M. B. 2004. MAPK regulation of sclerotial development in Sclerotinia sclerotiorum is linked with pH and cAMP sensing. Mol. Plant-Microbe Interact. 17:404-413.

Chen, S. L., Zhou, B. L., Lin, S. S., Li, X., and Ye, X. L. 2010. Effect of cinnamic acid and vanillin on grafted eggplant root growth and physiological characteristics. Chin. J. Appl. Ecol. 21:1446-1452.

Duan, Y. B., Ge, C. Y., Liu, S. M., Chen, C. J., and Zhou, M. G. 2013. Effect of phenylpyrrole fungicide fludioxonil on morphological and physiological characteristics of Sclerotinia sclerotiorum. Pestic. Biochem. Physiol. 106: 61-67.

Erental, A., Dickman, M. B., and Yarden, O. 2008. Sclerotial development in Sclerotinia sclerotiorum: Awakening molecular analysis of a "dormant" structure. Fungal Biol. Rev. 22:6-16.
Firoz, M. J., Xiao, X., Zhu, F., Fu, Y., Jiang, D., Schnabel, G., and Luo, C. X. 2016. Exploring mechanisms of resistance to dimethachlone in Sclerotinia sclerotiorum. Pest Manag. Sci. 72:770-779.

Godoy, G., Steadman, J. R., Dickman, M. B., and Dam, R. 1990. Use of mutants to demonstrate the role of oxalic acid in pathogenicity of Sclerotinia sclerotiorum on Phaseolus vulgaris. Physiol. Mol. Plant Pathol. 37:179-191.

Harel, A., Bercovich, S., and Yarden, O. 2006. Calcineurin is required for sclerotial development and pathogenicity of Sclerotinia sclerotiorum in an oxalic acidindependent manner. Mol. Plant-Microbe Interact. 19:682-693.

Hettiarachi, S. 2011. Biotechnology: A tool for natural product synthesis. Pages 263-279 in: Natural Products in Plant Pest Management. N. K. Dubey, ed. CAB International, Wallingford, U.K.

Hoskins, J. A. 1984. The occurrence, metabolism and toxicity of cinnamic acid and related compounds. J. Appl. Toxicol. 4:283-292.

Hou, Y. P., Mao, X. W., Lin, S. P., Song, X. S., Duan, Y. B., Wang, J. X., and Zhou, M. G. 2018. Activity of a novel succinate dehydrogenase inhibitor fungicide pyraziflumid against Sclerotinia sclerotiorum. Pestic. Biochem. Physiol. 145:22-28.

Jo, Y. K., Niver, A. L., Rimelspach, J. W., and Boehm, M. J. 2006. Fungicide sensitivity of Sclerotinia homoeocarpa from golf courses in Ohio. Plant Dis. 90:807-813.

Jurick, W. M., and Rollins, J. A. 2007. Deletion of the adenylate cyclase (sacl) gene affects multiple developmental pathways and pathogenicity in Sclerotinia sclerotiorum. Fungal Genet. Biol. 44:521-530.

Karimi, E., Jaafar, H. Z., and Ahmad, S. 2013. Antifungal, anti-inflammatory and cytotoxicity activities of three varieties of Labisia pumila Benth: From microwave obtained extracts. BMC Complement. Altern. Med. 4:19-25.

Liu, L., Hudgins, W. R., Shack, S., Yin, M. Q., and Samid, D. 1995. Cinnamic acid: A natural product with potential use in cancer intervention. Int. J. Cancer 62:345-350

Ma, H.-X. Feng, X.-J., Chen, Y., Chen, C.-J., and Zhou, M.-G. 2009. Occurrence and characterization of dimethachlon insensitivity in Sclerotinia sclerotiorum in Jiangsu Province of China. Plant Dis. 93:36-42.

Matkowski, A. 2008. Plant in vitro culture for the production of antioxidants-A review. Biotechnol. Adv. 26:548-560.

Mueller, D. S., Dorrance, A. E., Derksen, R. C., Ozkan, E., Kurle, J. E., Grau, C. R., Gaska, J. M., Hartman, G. L., Bradley, C. A., and Pedersen, W. L. 2002. Efficacy of fungicides on Sclerotinia sclerotiorum and their potential for control of Sclerotinia stem rot on soybean. Plant Dis. 86:26-31.

Pillonel, C., and Meyer, T. 1997. Effect of phenylpyrroles on glycerol accumulation and protein kinase activity of Neurospora crassa. Pestic. Sci. 49:229-236.

Purdy, L. H. 1979. Sclerotinia sclerotiorum: History, diseases and symptomatology, host range, geographic distribution, and impact. Phytopathology 69: $875-880$.

Rollins, J. A. 2003. The Sclerotinia sclerotiorum pac1 gene is required for sclerotial development and virulance. Mol. Plant-Microbe Interact. 16:785-795.

Rollins, J. A., and Dickman, M. B. 2001.pH signaling in Sclerotinia sclerotiorum: Identification of a pacC/RIM1 homolog. Appl. Environ. Microbiol. 67:75-81.

Shen, J. X., Fu, T. D., Tu, J. X., and Ma, C. Z. 2007. The potential of rapeseed production, genetic improvement and the development prospect of rapeseed biodiesel in China. J. Huazhong Agric. Univ. 26:894-899.

Shi, Y., Chen, Q. X., Wang, Q., Song, K. K., and Qiu, L. 2005. Inhibitory effects of cinnamic acid and its derivatives on the diphenolase activity of mushroom (Agaricus bisporus) tyrosinase. Food Chem. 92:707-712.

Shi, Z. Q., Zhou, M. G., and Ye, Z. Y. 2000. Resistance of Sclerotinia sclerotiorum to carbendazim and dimethachlon. Chin. J. Oil Crop Sci. 22:54-57.

Smith, F. D., Phipps, P. M., Stipes, R. J., and Brenneman, T. B. 1995. Significance of insensitivity of Sclerotinia minor to iprodione in control of Sclerotinia blight of peanut. Plant Dis. 79:517-523.

Sun, Y., Wang, Y., Xie, Z. Y., Guo, E. H., Han, L. R., Zhang, X., and Feng, J. T. 2017. Activity and biochemical characteristics of plant extract cuminic acid against Sclerotinia sclerotiorum. Crop Prot. 101:76-83.

Wang, Y., Duan, Y. B., Wang, J. X., and Zhou, M. G. 2015. A new point mutation in the iron-sulfur subunit of succinate dehydrogenase confers resistance to boscalid in Sclerotinia sclerotiorum. Mol. Plant Pathol. 16:653-661.

Wang, Y., Duan, Y. B., and Zhou, M. G. 2016. Baseline sensitivity and efficacy of fluazinam in controlling Sclerotinia stem rot of rapeseed. Eur. J. Plant Pathol. 144:337-343.

Wang, Y., Sun, Y., Zhang, Y., Zhang, Y. X., Han, L. R., Zhang, X., and Feng, J. T. 2017. Sensitivity and biochemical characteristics of Sclerotinia sclerotiorum, to propamidine. Pestic. Biochem. Physiol. 135:82-88.

Williams, B., Kabbage, M., Kim, H. J., Britt, R., and Dickman, M. B. 2011 Tipping the balance: Sclerotinia sclerotiorum secreted oxalic acid suppresses host defenses by manipulating the host redox environment. PLoS Pathog 7: e1002107.

Xu, C. Y., Liang, X. Y., Hou, Y. P., and Zhou, M. G. 2015. Effects of the novel fungicide benzothiostrobin on Sclerotinia sclerotiorum in the laboratory and on Sclerotinia stem rot in rape fields. Plant Dis. 99:969-975.

Yan, H., Xiong, Z., Xie, N., Liu, S. Z., Zhang, L. L., Xu, F., Guo, W. H., and Feng, J. T. 2018. Bioassay-guided isolation of antifungal amides against Sclerotinia sclerotiorum from the seeds of Clausena lansium. Ind. Crops Prod. 121:352-359.

Zhou, B. W., and Luo, Q. 1994. Page 346 in: Rapeseed Diseases and Control. China Commerce Publishing Co., Beijing. 